\section{Derecho y obligación. ¿Restricciones a la libertad?}

\author{
Right and Duty - Restrictions on Freedom?
}

\section{Klaus Vieweg}

\section{RESUMEN}

¿Se puede hablar filosóficamente de una limitación justificada de la libertad? La definición hegeliana del libre albedrío, fundamentada lógicamente, y su comprensión del derecho y la obligación puede contribuir a la clarificación del concepto de libertad. Importa diferenciar de manera precisa entre libertad y arbitrio-este último un elemento necesario, pero unilateral, de la voluntad libre. Con el arbitrio la voluntad no se encuentra todavía en la forma de razón. Los derechos y obligaciones racionales no son una restricción de la libertad. En la medida en que los derechos individuales pueden colisionar (por ejemplo, en situaciones de emergencia), puede haber una restricción temporal y proporcionada de ciertos derechos en favor de derechos más elevados, como el derecho a la vida. Las dictaduras son instancias de un ejercicio del poder del orden de lo arbitrario en las cuales se restringe la libertad. El Estado diseñado racionalmente, por el contrario, restringe únicamente el arbitrio. Lo que debe definirse son las obligaciones y los derechos del Estado y las obligaciones y derechos de los ciudadanos.

Palabras clave: libre albedrío; arbitrio; derecho y obligación; libertad; limitación

\section{ABSTRACT}

Can one speak philosophically of a justified limitation of freedom? Hegel's logically founded definition of free will and his understanding of right and duty can contribute to a clarification of the concept of freedom. Important is a precise differentiation between freedom and caprice (Willkür) - the latter being a necessary but one-sided element of the free will. In caprice, the will is not yet in the form of reason. Rational rights and duties are not a restriction of freedom. Insofar as individual rights can collide (e. g. in emergency situations), there can be a temporary and proportionate restriction of certain rights in favour of higher rights, such as the right to life. Dictatorships are instances of capricious rule which restrict freedom; the rationally designed state, by contrast, restricts only caprice. What is tobe defined are the duties and the rights of the state and the duties and the rights of the citizens.

Keywords: free will; caprice; right and duty; freedom; limitation
INFORMACIÓN

http://doi.org/10.46652/resistances.v2i4.69 ISSN 2737-6222 |

Vol. 2 No. 4, 2021, e21069

Quito, Ecuador

Enviado: noviembre 03, 2021 Aceptado: diciembre 15, 2021 Publicado: diciembre 29, 2021 Publicación continua

Sección dossier | Peer Reviewed

\section{(c) (i) $(9)$}

open 2 access

AUTOR

Klaus Vieweg Friedrich-Schiller-Universität Jena Alemania

klaus.vieweg@uni-jena.de

Conflicto de intereses

El autor declara que no existe conflicto de interés posible.

Financiamiento

No existió asistencia financiera de partes externas al presente artículo.

Agradecimiento

N/A

Nota

Traducción de Zaida Olvera (Universidad Autónoma del Estado de Morelos, México).
PUBLISHER 
Hace 200 años apareció la obra de Hegel más controvertida y con mayor influencia: los Principios Fundamentales de la filosofía del derecho. Este libro posee todavía en el siglo XXI una inquebrantable relevancia, pues contiene la teoría filosófica más profunda que hasta hoy se haya escrito sobre el querer libre y la acción. La filosofía tiene el derecho y la obligación de traer nuevamente hacia el Concepto el "universo ético" de los modernos, a la Constitución del mundo moderno; en particular, tiene el derecho y la obligación de determinar con más precisión el contenido del concepto de libertad: ¿Cuáles son los criterios y principios que califican para una acción libre, responsable y humana? ¿En dónde residen los baremos para la legalidad en los modernos? Se puede decir justificadamente que en los últimos años ha habido una Hegel rennaissance, o un permanente hegelian turn en la filosofía, o un commeback de Hegel. Esto es especialmente válido para la Filosofía del derecho, una obra que pertenece a la misma lista que la República de Platón, la Política de Aristóteles, el Leviatán de Hobbes, El contrato social de Rousseau o el concepto de razón práctica de Kant. Tanto la concepción de Hegel sobre la libertad como la pregunta sobre la manera en la que se debe determinar a la libertad a través del pensamiento conceptual en tanto que fundamento del universo práctico, son centrales. La actualidad perdurable y la modernidad del idealismo de la libertad de Hegel se manifiestan también con relación a un elemento fundamental de su pensamiento, a saber: el de la unidad de derecho y obligación.

La palabra libertad se encuentra en boca de todos. Se acoge uno a ella como a la Constitución. En relación con la regulación de la pandemia, se escuchan reclamos en contra de las "limitaciones a la libertad". Algunos movilizan a más no poder comparaciones con las dictaduras y con la ley habilitante de Hitler. El discurso público dominante sobre la libertad da pie a la reflexión filosófica ya que el saber sobre la palabra "libertad" todavía está lejos de ser el conocer el significado de la libertad. Este trabajo persigue dos fines prioritarios que se encuentran vinculados entre sí. Lo primero y más importante: mediante argumentos hegelianos se contribuirá a afinar nuestra comprensión del contenido sustancial de la libertad (Vieweg, 2012 y 2020). En particular, se trata de una determinación precisa de la relación entre libertad y arbitrio. ¿Se puede hablar filosóficamente de una justificación de la limitación de la libertad? En segundo lugar, se leerán de manera concisa los conceptos de libertad y derecho, así como la reciprocidad entre el derecho y la obligación como el trasfondo de la Constitución Alemana, en particular del artículo 1. La tesis es: el derecho racional puede ser aprehendido como el ser externo del libre albedrío, mas no como su limitación.

Pero primero hagamos algunas distinciones capitales entre libertad y libertad de elección (arbitrio): Kant habla de un libre arbitrio como una facultad "de hacer o dejar de hacer al antojo" (Kant 1907, 213)-sobre los puntos de vista de Kant y Hegel véase el instructivo comentario de Krijnen, 2018 -. Hegel anota en Nürnberg: “Cuando nos referimos a la libertad en la vida cotidiana entendemos por ella el arbitrio o la libertad relativa: el que yo pueda hacer o pueda dejar de hacer" (Hegel, 1970a, p. 226). Predomina la opinión según la cual "la libertad es esto: que se pueda hacer lo que se quiera" (Hegel, 1970b, 7. A partir de aquí citado como RPh, p. 6568). Desde este punto de vista, la libertad es equiparada con la posible elección de variantes del hacer, con la elección de posibilidades. Estas declaraciones son consideradas por Hegel como 
una falta de formación del pensamiento o como entendimiento superficial, y encierran una inesperada situación: “el arbitrio se llama comúnmente libertad; pero ciertamente, el arbitrio es solo la libertad irracional, el elegir y la autodeterminación que no provienen de la racionalidad de la voluntad" (Hegel, 1970c, p. 136). La libertad aparece como una situación en la que se puede hacer lo que se quiera- pero aquello que se quiere es lo que está precisamente en cuestión (Hegel, 1983, 64). Mediante esta reducción de la libertad a mero arbitrio todas las "limitaciones" del arbitrio, de esta presunta libertad, son (des)calificadas como coerción, como restricción, como intromisión o represión. "Es el punto de vista habitual el que a través del Estado el derecho es limitado en su libertad" (Hegel, 2005, 43). Esto mismo debe ser considerado como una concepción altamente limitada y obstinada.

\section{La estructura fundamental del libre albedrío.}

En un primer momento serán explicados a través de su elucidación tanto los tres parágrafos fundamentales 5 a 7 de la Filosofía del derecho de Hegel, así como su Introducción, siguiendo la exposición de los fundamentos lógicos del concepto de voluntad libre (Vieweg 2012, p. 57-96). Sólo de esta manera puede alcanzarse una adecuada interpretación del concepto de libertad en Hegel. La argumentación general se basa, de acuerdo con Hegel, “en el espíritu lógico” tal y como ha sido desarrollado en la Ciencia de la lógica (RPh, 12-13). Aquí entra en juego un amplio espectro de contenidos doctrinales de la Lógica: desde lo indeterminado y lo determinado, lo infinito y lo finito, la reflexión y el entendimiento, universalidad, particularidad y singularidad, finalidad, negación inmanente, hasta límite y deber (Sollen). Se investigará la comprensión hegeliana de los fundamentos de la libertad, la única determinación fundamental ("sustancia”) de la voluntad desde el especial punto de vista de la temática de la limitación - en palabras de Hegel: "limitación - tremendo error" (RPh, 82).

En el parágrafo 5 se hace explícito el momento ALFA: la indeterminidad pura. Ahí, la limitación parece diluida; se trata de la infinitud ilimitada de la abstracción absoluta o universalidad el pensamiento puro del Yo. El pensar y la voluntad no son dos facultades diferenciadas que se contraponen. Pero en ALFA se trata solamente de un lado de la voluntad, del lado de la posibilidad absoluta que prescinde de la determinidad. Ningún contenido puede fungir aquí como "límite". Más bien, todo lo determinado o particular de la voluntad aparece como limitación - en la primera universalidad la particularidad está presuntamente 'disuelta'. ALFA representa un momento indispensable de la libertad, pero el déficit del entendimiento reside en que ilícitamente hace de este elemento necesario el "único y más alto" (RPh, §51). Esta reducción de la voluntad libre es descrita por Hegel como la posición de la libertad negativa o vacía, es decir, como libertad propia del entendimiento.

En términos lógicos, se trata aquí de la exclusión buscada de la particularidad como contenido del querer, de la aseveración de la incompatibilidad entre el presunto universal puro y la particularidad, la cual ciertamente parece haberse hundido y desaparecido en la universalidad abstracta. Pero esta universalidad vacía en tanto que indeterminación es igualmente ya lo otro: "lo que piensa que es su negación", es decir, algo finito, unilateral, delimitado: "lo indeterminado es igualmente lo determinado, pues se le contrapone a lo determinado” (Hegel, 1983, §6o, 
subrayado en el original = Hegel, 2005, 44). Así pues, lo universal es puesto como lo particular, pero la particularidad del universal no es algo que se añade posteriormente, sino que es así desde el comienzo.

Al negar todos los límites yo mismo me limito, me vuelvo unilateral y, por tanto, soy meramente uno de los dos lados. En sentido lógico, el momento BETA, la particularidad, se encuentra ya en el momento ALFA. La primera palabra del §6 expresa lo anterior: Del mismo modo, el Yo es un particular, un determinado, es lo que mediante su querer pone contenido. BETA no introduce nada nuevo. Este segundo momento está ya contenido en el primero, y es solo un poner de lo que el primero ya es en sí. En tanto que lo primero, ALFA no es la verdadera infinitud y universalidad sino justamente solo algo determinado. Puesto que reclama la abstracción de toda determinidad, ALFA no queda exenta de determinidad. Precisamente, eso constituye su única determinidad y su vacuidad: ser abstracta, indeterminada - “aquella abstracción es el límite” (RPh, §54 [subrayado en el original]). El momento BETA, la particularidad, aparece como limitación de la dimensión de la voluntad descrita en ALFA, como la negación de la primera. Parece ahora como si la voluntad desistiese de su libertad (RPh, §54). En la mayoría de los casos, el entendimiento o la reflexión toman a lo supuestamente indeterminado, ilimitado, por lo óptimo, por lo más alto, por la propia libertad (RPh §53). Sin embargo, el tránsito de ALFA a BETA no es simplemente el camino hacia la limitación de algo ilimitado, sino que BETA conserva superando [hebt auf] incluso el "límite anterior", es decir, la universalidad abstracta - justamente así solo "un límite es intercambiado por otro” (RPh, §45). El resumen de Hegel es el siguiente: ALFA y BETA, lo indeterminado y lo determinado, lo infinito, así como lo finito, son limitaciones, unilateralidades, nos encontramos con "un ir y venir de un límite hacia otro" (RPh, §54). Ambos elementos son solo dos lados, indispensables pero deficientes de la determinación de la voluntad libre. Su dua-lidad [Zweiheit], su dualismo debe, por tanto, ser trascendido. La universalidad y particularidad deben ser conducidas a una un-idad [Ein-heit], es decir, en términos lógicos, 'unidas silogísticamente'.

Cada uno de estos primeros momentos, a saber: el momento en el que la voluntad abstrae de todo y el momento en el que ella está también determinada, se admite fácilmente, pero el tercer momento, el vincular lógico, especulativo, repulsa al entendimiento (RPh, $\S 55$ [subrayado en el original]).

Con frecuencia, la particularización es comprendida como un añadido y no precisamente como algo que en sentido estricto se deduce lógicamente. El entendimiento se conduce abstractamente y tiende a la separación, se apoltrona en el dualismo de los dos lados, permaneciendo así lo indeterminado y lo determinado de la voluntad como unilaterales. La deducción lógica, la unificación silogística de ALFA y BETA solo puede darse si el tercer momento, GAMMA, se encuentra ya presente tanto en ALFA como en BETA - la negatividad inmanente. Decisivo es que en el §7 Hegel apunta hacia la lógica del concepto en la Ciencia de la lógica, hacia la estructura lógica de la universalidad, la particularidad y la singularidad.

La universalidad ya se encuentra puesta de forma inmanente como particularidad, de la misma manera que la particularidad se encuentra puesta como universalidad - la voluntad se mantiene 
como a) ilimitada en la limitación, b) la universalidad se encuentra contenida en la particularidad y c) lo negativo permanece en lo positivo (Hegel, 1983, §61). GAMMA, en tanto que singularidad lógica, fija la verdadera autodeterminación - la de permanecer consigo, en su identidad consigo mismo, es decir, con lo universal, y al mismo tiempo ponerse como lo negativo de sí mismo, como determinado, limitado" (RPh, §57). En esta concepción de la libertad de la voluntad, ALFA y BETA representan los momentos 'indeterminidad' y 'determinidad' de GAMMA, que es el concepto concreto de la libertad.

\section{Autoactividad formal y la elección de variantes.}

La voluntad formal, la voluntad considerada desde la perspectiva del entendimiento, se encuentra en el paradigma de la autoconciencia, es decir, por un lado, en el dualismo de la voluntad en tanto que un poner metas subjetivo, y por el otro, como la relación de ella con el objeto dado, previamente ahí, o el 'descubrimiento de un mundo exterior'. Explícitamente, lo anterior no puede valer como la esencia de la libertad (por un lado, el kantiano autocomienzo de una situación, por otro, un reino de la causalidad (Krijnen, 2018). Hegel, abandonando el modelo de la conciencia, evoca decididamente el nuevo paradigma que ya se encuentra en juego, a saber: el espíritu. Nos encontramos en la esfera del espíritu (objetivo). El mero suponer, el puro encontrarse ya ahí del mundo sería unilateral sin la unidad con la generación o construcción de este mundo propia del concepto de espíritu (Cfr. Hegel, 1970, \$384, §386). La voluntad libre se tiene a sí misma como su objeto, sus determinaciones son las propias determinaciones inmanentes de la voluntad. El contenido es su "particularización reflejada en sí misma", es la unidad de la meta subjetiva interna - bajo la forma de la voluntad representadora, aquella que precisamente no es la voluntad pensante capaz de captar en conceptos - y la meta alcanzada - el poner de los momentos del concepto de libertad, la objetivación de las determinaciones en él contenidas (RPh, §59 [subrayado en el original]). Por el contrario, la separación del En sí y del Para sí presente en lo finito, orilla al entendimiento a preferir el ser-en-sí y a reducir la libertad a una capacidad, el poner absoluto de la posibilidad en tanto que presunta indeterminidad pura. Así, este punto de vista del entendimiento toma la relación con lo que es querido solo como una aplicación sobre un material dado, una aplicación sobre algo que no pertenece al núcleo de la libertad. En consecuencia, la limitación de la libertad residiría en la realización de una posibilidad. Nuevamente emerge aquí el aspecto abstracto de la libertad. El ser-en-sí en tanto que es lo supuestamente ilimitado, lo absolutamente abstracto, está, sin embargo, él mismo limitado, pues para limitar hacen falta dos - de ahí la repetida invocación a la dua-lidad [Zweiheit], al persistente modelo de la conciencia, al dualismo del entendimiento.

La voluntad, en principio inmediata, es lo mío, pero no inmediatamente bajo la forma de la racionalidad. En tanto que singular ( $\mathrm{RPh}$, §55), es comprendida como aquello que supera el estatus de la posibilidad, como la voluntad decidida y real efectiva. La decisión [Entschluss], la resolución [Ent-Schließen], significan el abrirse de lo anteriormente 'cerrado' [Verschlossenen] hacia la multiplicidad de las cosas particulares. Se trata de un elegir una opción que puede volverse real, la posibilidad de determinarse por esto o por aquello, la principal alternancia 
potencial del querer, del hacer. La posibilidad avanza ahora hacia la realidad efectiva. Sin embargo, el contenido elegido no debe ser per se un contenido racional, no necesariamente un contenido de la libertad. Tal libertad de la voluntad es, desde estas determinaciones preliminares de la libertad de elección, el arbitrio.

Hegel describe estos niveles como la auto-actividad formal, el elemento formal de la libre autodeterminación. Del pool de las posibilidades se escoge, se selecciona una variante. Se trata de la elección de la voluntad mediante la cual un contenido es elegido. Los príncipes electores eligen, optan por un determinado candidato para que éste se vuelva el rey. 'Quiero porque es esto lo que quiero' - determinar a Guillermo o Federico como el rey - Mediante este acto soberano puedo también decidir algo más. En el libre arbitrio aparece también la contingencia bajo la forma del querer. La voluntad no se determina a través del concepto de la voluntad (RPh, §67), ella aún no se tiene a sí misma como su propio contenido; éste es al principio tan sólo hallado. El contenido puede ser racional o no. Mediante la equiparación del arbitrio y de la libertad nos veríamos obligados a caracterizar como acciones libres el crimen o el terror, pues eso fue elegido por el agente. Se trata, por consiguiente, solo de la certeza abstracta que la voluntad posee de su libertad, pero no todavía de la voluntad libre plenamente determinada. Ésta no puede residir exclusivamente en la certeza, sino en el pensamiento racional. En tanto que arbitrio, la voluntad es concebida por Hegel como contradicción, una contradicción necesaria, pero momento insuficiente de la libertad.

Sólo la voluntad racionalmente determinada puede ser considerada como voluntad libre, sobre la base de la unificación pensante entre universalidad y particularidad, de la superación del dualismo sostenido por el entendimiento entre los momentos ALFA y BETA y de la superación de la voluntad reflexionante. Hegel insiste en el "pensamiento que se impone en la voluntad", en el pensamiento conceptual (RPh, §72). Quien aquí, en este punto neurálgico de la comprensión filosófica de la libertad, recurre a otras instancias como la mera opinión, el entusiasmo o el sentimiento, en lugar de recurrir a este pensamiento, en lugar de recurrir al saber y a la ciencia, le roba al ser humano "toda verdad, valor y dignidad” (RPh, §73).

Más tarde, en §140, Hegel se refiere a la "subjetividad absoluta y auto-afirmante", la cual sólo opina y asegura. Este puro dogmatismo del opinar rechaza decididamente el poner a prueba y el demostrar. El convencimiento subjetivo, la propia discrecionalidad, vale como único fundamento de determinación del actuar. En lugar del saber examinado se coloca cualquier clase de objetividad, 'vanidad superficial', teniendo como resultado la arbitrariedad del relativismo que domina hoy en día. Lo anterior va acompañado del descrédito y la degradación de la verdad y la ciencia, el rebajamiento de la filosofía a un juego sin fuerza vinculante -aquí y ahora vale esto, mañana aquello y pasado mañana aquello otro- y así hasta el día del juicio final. Sobre todo, lo intocable, inviolable, inalienable, incondicional y eterno pesa la sospecha de ser pura metafísica. Nos las habemos con la arrogantia, la búsqueda de sí mismo (amour-propre), la vanidad, el arbitrio en su total ilimitación; con una subjetividad que se empecina con su validez única. "En la hoguera de las vanidades se consume todo lo que vale por sí mismo" (Hegel, 2005, 142). Mi buen corazón, mi buen punto de vista, la plausibilidad de mi convicción interior debe ofrecer una total 
justificación de los actos. Cuando a alguien se le ocurre invocar la posibilidad del error, así reza la respuesta: “errar es de humanos”. En ello ve Hegel fraudulencia, pues en primer lugar se valora la relatividad como lo más alto y sagrado, pero, en un segundo momento, eso es considerado como lo más insignificante, como lo casual o equivocado - "si no puedo conocer lo verdadero entonces es indiferente cómo piense" (RPh, §276 [subrayado en el original]). Esta visión de una tolerancia que se presenta a sí misma como diversidad y apertura en el sentido de indiferencia de todo contenido particular (RPh, \$282) conduciría a que no pueda haber ya "ningún juicio racional sobre el bien y el mal, ninguna resolución venerable o despreciable". La razón y la sinrazón tendrían los mismos derechos - una tolerancia semejante sería una tolerancia excluyente, en beneficio de lo irracional (RPh, \$274 [subrayado en original)]. Quien antepone el capricho del mero arbitrio - cada cosa relativa, cada particularidad, cada época, cada cultura, etc., tiene su propia verdad - a un saber que ha sido examinado, rinde homenaje al relativismo a la moda que, sin embargo, se refuta a sí mismo, y pone masivamente en peligro el proyecto moderno de la libertad.

La voluntad racional sustentada en el pensamiento conceptual presenta una relación consigo misma, una autodeterminación de la voluntad: la voluntad libre que quiere la voluntad libre (RPh §27). La existencia del libre albedrío es englobada categorialmente por Hegel como Derecho y la libertad como idea, como su concepto y realización. Las determinaciones de la voluntad se expresan como formaciones y niveles del derecho: el sistema del derecho conceptualizado se expresa como 'reino de la libertad realizada'. Decisivo es que este derecho racional, y la obligación que va ligada inseparablemente a él, no se consideren como una limitación de la libertad en ningún sentido. La doctrina del derecho es a su vez, y de manera inmanente, doctrina de la obligación. No hay derechos sin obligaciones y viceversa. En cuanto a la eticidad como el más alto nivel del derecho, Hegel afirma que las determinaciones del derecho corresponden a las obligaciones vinculantes de los actores: no se necesita permanentemente el dictum "también es esta determinación un deber para el ser humano" (RPh, \$297 [subrayado en el original]). En la identidad que se da dentro de la voluntad en tanto que singular entre voluntad universal y voluntad particular, el derecho y la obligación se vuelven uno. A través de lo ético el ser humano posee derechos en la medida en que tiene obligaciones, y obligaciones en la medida en que tiene derechos (RPh, §304, subrayado en el original). La obligación no es, en ningún sentido, una limitación de la libertad, sino solo limitación de la abstracción de ésta, es decir, de la ausencia de libertad: “el haber ganado la determinación de la libertad afirmativa” (RPh, §298). El derecho y la obligación limitan el arbitrio, en la medida en que éste es libertad formal abstracta. En el derecho que se presenta racionalmente y en su correspondiente obligación nos las habemos con la liberación de los individuos hacia la libertad substancial. La perspectiva de la libertad negativa hace válida la perspectiva según la cual la libertad se restringiría a través del derecho, la obligación o el Estado. Cuando la definición del derecho se basa en la voluntad del individuo particular, cuando éste es considerado como el punto de partida, lo primero y lo substancial, lo racional solo puede concebirse como la limitación de la libertad. En cambio, Hegel afirma nuevamente que en el reino del derecho los límites han sido superados y conservados. El derecho racional no conlleva una limitación de la libertad. Las determinaciones del derecho no son lo negativo, lo limitante de la libertad; más bien la libertad está presente en el derecho. 
La aparente pequeña diferencia entre libertad de elección (arbitrio) y la libertad verdadera, basada en la razón, cobra una relevancia fundamental. Hegel concibe las leyes racionales y las directrices como los instrumentos para limitar el arbitrio, el capricho obstinado, pero en ninguna medida como limitaciones para la libertad.

\section{El pulular del arbitrio.}

Una amenaza particular para un concepto moderno de la libertad emerge desde la ideología del fundamentalismo de mercado, especialmente cuando la libertad es reducida a libertad de elección. El mercado, como 'pulular del arbitrio', como sistema 'en su extrema pérdida de eticidad', en tanto que comunidad de necesidades y como comunidad de entendimiento, es descrito como libertad. Por ello, su regulación racional y su estructuración son la condición de su permanencia (Stiglitz, 2010; Vieweg, 2012). Esta estructura de lo fortuito y de lo arbitrario propia del imperio de la particularidad, en tanto que espacio de lo heterónomo y de lo contingente, no puede regularse ni gestionarse a sí misma de manera suficiente, pues tiende al deterioro y a la negación. Tal y como ocurre en el entendimiento, así también ocurre en esta estructura del entendimiento que las determinaciones se encuentran infundadas y tambaleantes, y el edificio construido sobre ello se viene abajo sin regulación racional. La dominación del arbitrio que caracteriza al mercado se extravía en el progreso infinito, en la mala infinitud, el quid lógico del entendimiento. Lo anterior conduce a la desmesura: arbitrio, opinión, riqueza y pobreza no tienen medida.

El Estado, por el contrario, es reducido a instituciones, se sostiene que limita con coerción el hacer libre. Los protagonistas de la doctrina pura de la autoregulación y capaz de auto-corregirse celebran al mercado como el verdadero grial de la libertad. Sin embargo, evidentemente se trata de una dependencia arbitrio-casual que no está ni para satanizarse ni para prenderle inciensos. A pesar de que es un importante posibilitador de la libertad, al mercado no puede atribuírsele de ninguna manera el atributo libre. Una distorsión tan insostenible como esa de la libertad, sumada al elogio apologético del supuesto libre mercado, así como el descrédito y lectura erradas del Estado, ocasiona desde hace siglos un virus pandémico.

\section{Derechos determinados y la posibilidad de una colisión entre derechos.}

A través de la determinación ulterior del concepto de derecho, de los niveles del derecho abstracto, la moralidad y de la eticidad, se desarrolla un sistema de determinados derechos particulares - desde derecho a la vida hasta los derechos políticos. En esta sección, la atención se encuentra dirigida a indicar los nexos relevantes entre la comprensión del derecho por parte del pensador de la Constitución, Hegel, y la Constitución Alemana. El concepto de dignidad humana, que es una parte fundamental de esta Constitución, se refiere a pensamientos centrales del derecho racional (Gutmann, 2010, p. 2). Hegel es, sin duda, un representante preminente de esta corriente. En los Estados modernos, la "definición del ser humano" como un ser libre puede colocarse en la "cima del código" (RPh, 33). En un comentario del Tribunal Constitucional 
Federal [N.T. A partir de aquí TCF] al artículo 1 de la Constitución Alemana- "La dignidad del ser humano es sagrada" - se lee, en una vena muy hegeliana: “La protección de la dignidad humana supone concebir al ser humano como un ser espiritual y ético, lo que está dirigido a que éste se determine y desarrolle en libertad." (TCF, Fallo del TCF, 45, 187, y 227. Fallo del TCF, 133, 168 y 197).

También con relación al asunto de los límites vale la pena echar un vistazo a la Constitución Alemana. Los derechos particulares, al efectuarse, pueden colisionar en situaciones determinadas. Los derechos sustanciales de la libertad de expresión y de prensa (Art. 4-5 TCF) tienen sus límites en la Constitución. Esto significa que no porque así lo dicte mi arbitro o mi buen juicio me está permitido decir o publicar cualquier cosa. El negacionismo respecto al holocausto o la incitación al odio contra grupos étnicos o nacionales no son libre expresión. La libertad del arte y de la ciencia se encuentra vinculada al contenido de la Constitución, en particular a la sacrosanta e inviolable dignidad del ser humano. Quien la pone en tela de juicio no puede invocar aquellos derechos mencionados. El artículo 88 de la Constitución que versa sobre la libertad de asociación se mantiene, con la salvedad de que este derecho pueda restringirse por ley. Los derechos a la libre circulación e inviolabilidad de la vivienda mantenidos en el artículo 11 y 13 de la Constitución pueden limitarse razonablemente durante un tiempo determinado por motivos de seguridad, como el riesgo epidemiológico, referido explícitamente.

El derecho a la vida constituye un principio decisivo de la teoría hegeliana de la personalidad. "Cada uno tiene el derecho a la vida y a la integridad corporal" (art. 2 (2) de la Constitución). Este mandamiento que comanda la inviolabilidad y la integridad de cada persona posee la forma de una orden de omisión, a saber: la prohibición de perjudicar o lastimar dicha personalidad: "la libertad de la persona es inviolable" (Art. 2 (2) de la Constitución. Sin embargo, pueden fijarse salvedades para esta ley). Con el derecho a la vida se fija un derecho fundamental, cuya violación afecta al resto de los derechos e incluso, dado el caso, los limita o excluye. Esto último aplica al menos momentáneamente, a situaciones de excepción graves, situaciones de extrema necesidad, en las cuales la vida se ve gravemente amenazada, como en una peligrosa catástrofe natural, una guerra, una pandemia, u otras amenazas globales a la vida. Llegamos aquí a la 'negociación’ en relación con la totalidad de los derechos determinados, pues se puede llegar a limitaciones temporales, adaptadas y proporcionales de los derechos habituales, como el de asociación o el derecho a la libre circulación. En situaciones de emergencia como inundaciones, terremotos o erupciones volcánicas existen prohibiciones definidas para los determinados ámbitos y áreas de seguridad ciudadana; lo mismo ocurre con fugas de sustancias tóxicas. Para las estaciones de infección de los hospitales existen desde tiempo atrás reglas exitosas de protección que regulan la vestimenta, el contacto y determinadas prohibiciones para la realización de visitas. Para los infectados aplican determinaciones limitadas de cuarentena, las cuales pueden incluso imponerse en contra de la voluntad de la persona en cuestión.

Hegel demuestra la posible colisión entre derechos mediante el hurto famélico: cuando, por ejemplo, una persona gravemente hambrienta roba un pan, eso es, de acuerdo con Hegel, su derecho. "El derecho debe tener vida" (RPh, §241). Cuando un ser humano se encuentra 
en una situación tal de excepción, "salva su vida gracias a que hurta una pequeña porción de otro propietario, sin que ello sea algo injusto. $Y$ no se trata de equidad, sino de derechos determinados. La vida es un momento absoluto en la idea de la libertad" (Hegel, 2005, 126 [subrayado en el original]). Si fuese violentado un determinado derecho, el derecho de propiedad para, no obstante, ejercer un derecho superior, "se encuentra justificada la conservación de cualquier bien cuya destrucción significara una infracción jurídica más grande." (Bockelmann, 1935, 22). Las modificaciones en la estructura global del derecho particular están reguladas por la Constitución y con relación a las pandemias y epidemia se regulan mediante una ley especial sobre la protección para las infecciones, misma que representa una ley de defensa frente a peligros para la vida. En el caso de pandemias pueden entrar en colisión el derecho a la vida con, por ejemplo, el derecho a la libre circulación o de reunión. "La vida tiene derecho frente al derecho en estricto sentido" (Hegel, 2005, 126). En relación con el cuidado de la vida, se trata de un derecho humano inmutable en el sentido pleno y universal de justicia; se trata de un derecho fundamental del cuidado frente a daños, enfermedades o frente a la destrucción de las condiciones naturales de la vida. "Si la vida se pierde, se instituye la ilegalidad" (Angehrn et al, 2000, p. 61). Las personas que, al oponerse a las medidas para la contención de la pandemia provocada por el Sars-CoV-2, ejercen el derecho a participar de manifestaciones, ciertamente no desisten en ellas (aunque a menudo no lo declaren en forma expresa) de su derecho a la vida. Durante estas acciones, el Estado tiene el deber de proteger su integridad. Los participantes esperan, obviamente, no ser golpeados o disparados. Sin embargo, cuando estas mismas personas amenazan la salud de otros, e incluso la de sus propios hijos, cuando los exponen al peligro de la infección, al tiroteo de virus, destruyen su propia posición, su propio derecho, el derecho de los demás y el derecho en sentido general. Un ejemplo de tal inversión de las propias exigencias lo ofrece Robert Pippin:

\begin{abstract}
Alguien, jugando ajedrez, que ha movido la torre en diagonal e intenta justificar su autoridad para hacerlo. El punto no es que está violando lo que todo el mundo puede ver en su objeto ideal "ajedrez", sino que está incurriendo en una contradicción consigo mismo, con su propio acuerdo de jugar ajedrez y con todo aquello a lo que lo compromete. En efecto, se está 'cancelando a sí mismo', nulifica su propia agencia con la pretensión de agencia (Pippin, 2008, 74).
\end{abstract}

En este contexto, Hegel sigue el teorema de Kant de la segunda coacción (RPh, §179 y sig.) (ver también Vieweg, 2012, p. 136-144). Una primera coacción es injusta, pero será superada y conservada bajo una segunda coacción, como lo que ocurre en el crimen a través de la pena. Si se pretenden derechos, se les deben reconocer también a todas las demás personas, se tiene la obligación de hacerlo. Las reglas racionales constriñen absolutamente la primera coacción, es decir, por ejemplo, la irracionalidad antes mencionada. El saber examinado debe vencer a la mera opinión. Sin embargo, esta segunda coerción racional no es represiva y no debe ser vista de manera peyorativa. La primera coerción injusta es, de acuerdo con Kant, "un impedimento u obstáculo que le ocurre a la libertad", la coerción opuesta podría ser vista como un impedimento a la obstaculización de la libertad, de donde resulta la facultad para coaccionar la primera coerción (Kant, 1907, p. 231-233). 


\section{Desarrollo de las determinaciones del derecho y la obligación.}

El desarrollo de las determinaciones de la voluntad en la forma de un sistema de derechos solo puede esbozarse aquí en líneas generales. En el $\$ 486$ de la Enciclopedia de Hegel se insiste nuevamente en el derecho como la manifestación exterior de la voluntad libre, como exteriorización de todas las determinaciones de la libertad; esto vale también para la obligación. "Un derecho es lo mismo que una obligación, y lo que una obligación es, es también un derecho" (Hegel, 1970d, 304). En la Filosofía del Derecho, la relación entre derecho y obligación es desarrollada progresivamente desde el nivel de la correlación: "un derecho de mi lado corresponde a una obligación del otro" y viceversa (Hegel, 1970d [subrayado en el original]). En la esfera de la moralidad, la obligación moral en mí es a su vez un derecho de mi voluntad subjetiva. De ello resulta la diferencia entre determinaciones de la voluntad que son solo internas, las obligaciones subjetivas, y su realidad efectiva, la cual constituye la contingencia e insuficiencia, la unilateralidad del mero punto de vista moral. En el terreno de la eticidad son capaces "el derecho y la obligación de invertirse mutuamente a través de la mediación y fusionarse" (Hegel, 1970d, \$305 [subrayado en el original]). Este camino de la mediación a través del cual las obligaciones de los actores regresan a sí mismas como ejercicio y disfrute de derechos sólo produce la apariencia de la diferencia o de la 'asimetría' entre derecho y obligación; sin embargo, el valor de ambos es el mismo, a pesar de las diferencias en las formas. En relación con lo dicho se ofrecen sólo algunos ejemplos: los ciudadanos tienen derecho a una buena administración y a buenas garantías de seguridad a través del Estado. Esto va ligado a la obligación del financiamiento de las instituciones (la obligación de pagar impuestos, por ejemplo). El derecho a un buen sistema de salud estará acompañado de la obligación de un seguro contra enfermedades; el derecho al ejercicio profesional implica la obligación de la formación profesional.

Un ejemplo para el juego entre derecho y obligación es la situación de la crianza en la familia y en el Estado en tanto que esferas de la eticidad. Las obligaciones son relaciones vinculantes. Para la voluntad del sujeto son vinculantes en el sentido de que son 'válidas' así como también en el sentido de que fusionan a los sujetos ob-ligados. El artículo 6 constitucional formula el cuidado y la crianza de los hijos como un derecho de los padres y como un deber que los obliga. Un principio fundamental subyace en los derechos de los niños: el derecho al bienestar y a la crianza y educación, el derecho a desarrollarse como seres humanos autodeterminados (Cfr. Convención de la ONU de 1989 sobre los derechos de los niños, donde se fijaron sus exigencias concretas). Los niños son en sí mismos libres, de manera que no son cosas o esclavos. Poseen el derecho de ser educados para volverse personas libres, autónomas. Este proceso de la crianza lo entiende Hegel como un "segundo nacimiento espiritual de los niños" (Hegel, 197od, \$521, subrayado en el original). La presencia inherente de la razón en el niño en tanto que ser humano puede realizarse mediante la crianza y la educación. Los derechos están vinculados con las obligaciones de los niños, como los deberes escolares, el deber de respetar las reglas de la escuela, aceptar el saber. La voluntad de los niños está masivamente cargada de inclinaciones naturales. La voluntad no es aún autosuficiente y racional y, en esa medida, no está presente todavía ninguna consideración suficientemente formada sobre si una acción es buena o mala. La 
crianza equivale de este modo a la segunda coerción legítima en contra de la constitución originaria de los niños y debe de ser considerada y presentada no como la limitación de su libertad, sino como la limitación del capricho de las inclinaciones y del arbitrio; debe de considerarse como el camino hacia la liberación de su voluntad, hacia la autonomía y la autodeterminación.

Aquí también cabe hablar de la coerción en pos de lo universal, la cual no debe ser considerada como represiva. Un principio fundamental es, por ejemplo, la autoridad del saber. Para la educación de una personalidad autónoma, ésta debe poder probar la autoridad del saber que ha recibido y manifestarse en contra de la autoridad de lo ahí meramente dado; de lo contrario no puede emerger ningún nuevo sujeto de voluntad consciente. Los derechos correspondientes de los tutores son inseparables de sus obligaciones, de las garantías de bienestar, de crianza y educación. Asimismo, se deben de colocar límites al posible arbitrio de los educandos. Los niños no son objeto de represión, de violencia, de maltrato. Esos casos pueden tener como consecuencia la revocación de la custodia como una segunda coerción en contra de la primera, e inhumana coerción: el sometimiento de un niño.

Al acudir con sus hijos a las manifestaciones, con lo cual se infringen las reglas para la preservación de la salud, los negadores de la pandemia ocasionada por el Sars-CoV-2 infringen su obligación, pues ponen conscientemente en riesgo la salud de sus hijos. La intervención estatal contra tales faltas a las obligaciones de crianza es uno de los derechos institucionales del Estado frente a los miembros de una comunidad educativa, a saber: el de asegurar la crianza [Erziehung] y educación [Bildung], por ejemplo, mediante la implementación de la escolaridad obligatoria como una segunda coerción contra el posible capricho de padres y niños. De igual manera, el Estado tiene la obligación de organizar y garantizar una educación pública adecuada para todos los niños, y de garantizar el ejercicio de los derechos de niños y de padres - un criterio para todo Estado moderno. Quienes tienen derecho a la educación [Erziehungsberechtigte] pueden ser llamados también los que tienen la obligación de educarse [Erziehungspflichtige]. A través de todos estos derechos y obligaciones propios al proceso educativo se restringe el arbitrio; se trata de la realización y desarrollo de la libertad mas no de su limitación.

\section{6. ¿El Estado como limitador de la libertad?}

Una concepción que es habitual escuchar hoy en día pretende que las leyes y regulaciones estatales limitan mi actuar libre. El slogan de los fundamentalistas del mercado es: 'Necesitamos menos Estado', lo cual implica la idea 'Necesitamos menos razón'. Esto es peligroso para una cultura política de la libertad, pues conduce a una suerte de hartazgo del Estado y de oposición al mismo. El Estado aparece como un limitador legal de la libertad que puede conducirse a través de la represión. Con ello puede producirse un distanciamiento y un abandono, por parte de los ciudadanos, de la tarea de organizar racionalmente sus asuntos comunitarios.

Se cree que "cada uno debería limitar su libertad con relación a la libertad de los demás y que el Estado sería la encarnación de esta limitación recíproca y las leyes, los límites mismos” (RPh, $\$ 539$ [subrayado en el original]). En una tesis tal, la libertad se reduce al capricho casual y al arbitrio. Pero es justamente este último el que debe limitarse. “El Estado no es ningún limitante 
de la libertad, a través de la limitación de la voluntad natural el ser humano debe llegar a ser libre" (RPh, 2005, §233). El Estado debe entonces ser comprendido y organizado en tanto que la forma de la autodeterminación, bajo la forma de una segunda coerción autoejercida en contra de la inaceptable primera coerción del arbitrio. Obedecer leyes racionales y soberanamente promulgadas y, en esa comunidad política, poder mantenerse en su alteridad idéntico consigo mismo, es lo que constituye la autodeterminación y la libertad política de los ciudadanos. Hegel ve en el Estado una fusión basada en el saber y en la razón. Los ciudadanos como sujetos de voluntad racionales son ellos mismos la vitalidad, la actividad y la realidad efectiva del Estado, del Estado como su vida universal. El Estado es para Hegel, en primer lugar, cada uno de los ciudadanos en su estatus de ciudadanos, en su ser-ciudadanos, en su ser-citoyen (Cfr. Vieweg, 2012, p. 350-365). En segundo lugar, el Estado es una formación de diferentes tipos de instituciones que tienen por misión garantizar la libertad de todos los singulares particulares. Aquí aparece un amplio y complejo entramado de derechos y obligaciones que se median entre sí.

El determinar apropiadamente las obligaciones del Estado y los derechos de los ciudadanos, así como los derechos del Estado y las obligaciones de los ciudadanos y que a través del pensamiento y de la racionalidad éstos se encuentren sustentados es, de acuerdo con Hegel, infinitamente importante y constituye el refinado arte de la formación de la moderna estatalidad libre (RPh, §406). El criterio para lo racional reside aquí en el aseguramiento y la garantía de la libertad de todos los individuos particulares dentro del Estado moderno, lo cual abarca la justicia y el vínculo entre un Estado de derecho y un Estado social, entre sustentabilidad natural y social. Con estos criterios deben medirse todos los Estados existentes.

La sociedad y su formación [Formierung] política es el espacio en el que el derecho tiene su realidad efectiva. Lo que debe limitarse y sacrificarse es precisamente el arbitrio y la violencia de la ilegalidad. Déspotas y dictadores limitan la libertad; en este contexto puede hablarse de leyes habilitantes y de despotismo del arbitrio. En cambio, el Estado fundado en el derecho racional, el Estado formado racionalmente, limita el mero capricho y el arbitrio de tal manera que gracias a ello pueda hacer valer, en tanto que Estado, la libertad. Si en los Estados ya existentes llegara a propagarse el menosprecio populista de los derechos y del saber y la rescisión del consenso democrático, se recaería en un nuevo tipo de estado de naturaleza - en un bellum omnium contra omnes, por ejemplo, bajo la figura de guerras civiles. No son el derecho basado en el pensamiento conceptual o el Estado formado racionalmente los que limitan y amenazan la libertad, sino quienes desprecian el saber y reducen la libertad a arbitrariedad. El capricho carente de pensamiento y lo bienpensante, los supuestos sin examinar y las meras afirmaciones pueden conducirnos a la estupidocracia, a la dictadura de lo irracional y al despotismo de la pseudoeducación. Como 'vacuna' para inmunizarnos en contra de estos virus se encuentran a nuestra disposición la reflexión, el saber y la educación. 


\section{Referencias}

Angehrn, E., Bondeli, M., \& Seelmann, H. N. (Hg.) (2000). Vorlesungen über die Philosophie des Rechts [Berlin 1819/20 in einer Nachschrift v. Ringier, J. R.], Hamburg.

Bockelmann, P. (1935). Hegels Notstandslehre. De Gruyter \& Co.

Gutmann, T. (2010). Struktur und Funktion der Menschenwürde als Rechtsbegriff. Preprints of the Centre for Advanced Studies in Bioethics.

Hegel, G. W. F. (1969 ff.). Theorie Werkausgabe. Auf der Grundlage der Werke von 1832-1845 neu edierte Ausgabe, Redaktion E. Moldenhauer \& K. M. Michel. Frankfurt am Main [TWA].

Hegel, G. W. F. (1970a). Rechts-, Pflichten und Religionslehre für die Unterklasse, In TWA 4, (pp. 204-274).

Hegel, G. W. F. (1970b). Grundlinien der Philosophie des Rechts, In TWA 7, (pp. 1-531).

Hegel, G. W. F. (1970c). Vorlesungen über die Ästhetik, In TWA 13, (pp. 1-546).

Hegel, G. W. F. (1970d). Enzyklopädie der philosophischen Wissenschaften, In TWA 10, (pp. 1-432).

Hegel, G. W. F. (1983). Philosophie des Rechts. Die Vorlesung von 1819/20 in einer. Nachschrift, hg. v. D. Henrich. Frankfurt am Main.

Hegel, G. W. F. (2005). Die Philosophie des Rechts, hg. v. H. Hoppe. Frankfurt am Main.

Kant, I. (1907). Metaphysik der Sitten [1. Aufl. 1797]. In: Werke 6, hg. v. d. Preußischen Akad. d. Wiss.

Krijnen, C. (2018). Die Wirklichkeit der Freiheit begreifen. Hegels Begriff von Sittlichkeit als Voraussetzung der Sittlichkeitskonzeption Kants. Folia Philosophica Katowice, 39, 37-144. https://journals.us.edu.pl/index.php/FOLIA/article/view/7469

Pippin, R. (2008). Hegel's Practical Philosophy. Cambridge.

Stiglitz, J. (2010). Im freien Fall: Vom Versagen der Märkte zur Neuordnung der Weltwirtschaft. Pantheon Verlag.

Vieweg, K. (2012). Das Denken der Freiheit. Hegels Grundlinien der Philosophie des Rechts. Fink Wilhelm $\mathrm{GmbH}$.

Vieweg, K. (2019). Hegel - Der Philosoph der Freiheit. C.H.Beck.

Vieweg, K. (2020). The Idealism of Freedom. For a Hegelian Turn in Philosophy. Brill

\section{AUTOR}

Klaus Vieweg. Estudió filosofía en la Friedrich-Schiller-Universität Jena (1970), se doctoró (1980) en la Humboldt-Universität Berlin e hizo su habilitación (1987) en la Universität Jena. Desde 1980 es profesor de filosofía clásica alemana en la Universität Jena. Ha sido profesor invitado o becario en universidades Erlangen, Tübingen, Bochum, Praga, Pisa, Medellín, Kyoto, Tokio, Shanghai, Roma, Seattle, entre otras ciudades 